\title{
Barriers to Tuberculosis Care Delivery among Miners and their Families in South Africa: an ethnographic study
}

L. V. Adams ${ }^{1}$, D. Basu ${ }^{2,3}$, S. W. Grande ${ }^{4}$, S. R. Craig ${ }^{5}$, M. T. Patridge ${ }^{4}$, N. Panth ${ }^{4}$, V. Trump

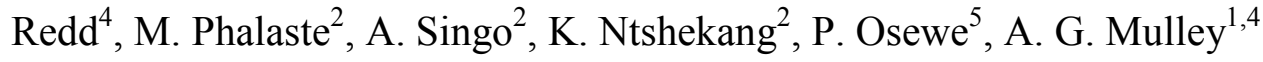

${ }^{1}$ Dartmouth's Geisel School of Medicine, Hanover, NH, USA; ${ }^{2}$ University of the Witwatersrand, Johannesburg, South Africa; ${ }^{3}$ University of Pretoria, Pretoria, South Africa; ${ }^{4}$ The Dartmouth Institute for Health Policy and Clinical Practice, Hanover, NH, USA; ${ }^{5}$ Dartmouth College, Hanover, NH, USA; ${ }^{5}$ The World Bank, Pretoria, South Africa

Corresponding author: Lisa V. Adams, MD; Associate Dean for Global Health; The Geisel School of Medicine at Dartmouth; 1 Rope Ferry Road, Room 219; Hanover, NH 03755 Tel: (603) 650-6060; Fax: (603) 650-6199; Email: Lisa.V.Adams@Dartmouth.edu

Running head: the TB experience among South African miners

Summary Word Count: 204

Text World Count: 3,500

Number of References: 43

Number of Tables: 2

Number of Figures: 0 


\section{Summary}

Setting: South African miners suffer the highest tuberculosis (TB) rates in the world. Current efforts to stem the epidemic are insufficient. Historical legacies and persistent disease burden demand innovative approaches to reshape healthcare delivery to better serve this population. Objective: To characterize social and behavioral health determinants for successful TB care delivery and treatment from the perspective of miners/ex-miners, healthcare workers and policymakers/managers.

Design: We conducted an applied ethnography with 30 miners/ex-miners, 13 family/community members, 14 healthcare providers, and 47 local policymakers/managers in South Africa. Results: Miners/ex-miners felt healthcare delivery systems fail to meet their needs. Many experience unnecessary physical and psychological harm due to limited health education about $\mathrm{TB}$, minimal engagement in their own care, a lack of trust in providers, and a system that does not value their experience. Stigma and fear associated with TB result in denial of symptoms and delays in care-seeking. Healthcare providers and policymakers/managers felt discouraged by system constraints to provide optimal care.

Conclusion: Our findings describe long-term effects of perpetual TB misinformation and stigma resulting from fear and disempowerment among miners and their families/communities. To reduce the TB burden, there is an urgent need to co-design with miners a care delivery system to better meet their needs.

Key words (max 5): Tuberculosis, miners, South Africa, stigma, healthcare delivery 


\section{Background}

With an estimated incidence of 3,000 per 100,000, miners in southern Africa have the highest tuberculosis (TB) rate in the world. ${ }^{1}$ Mines are the ideal setting for maximizing TB transmission and disease progression. Miners work long hours in enclosed spaces with poor ventilation. Limited sunlight and crowded dormitories allow TB bacilli to thrive and pass between coworkers. HIV infection and silica dust exposure, which affect approximately $25 \%$ of miners, each increases the chance of progression from TB infection to disease 30 -fold. ${ }^{2-6}$ Furthermore, an estimated $60 \%$ of miners are migrants, predominantly from Lesotho, Mozambique, and Swaziland, who leave their families and cross the South African border for employment. ${ }^{7}$ The absence of cross-border referral systems contributes to cycles of interrupted or incomplete treatment and TB transmission in miners' home communities.

Given their geographic concentration and high burden of disease, South African miners have been the subject of much TB research, primarily clinical and epidemiological studies. ${ }^{8-10}$ While this work has advanced our knowledge of the TB epidemic and provided evidence for the effectiveness of interventions such as isoniazid preventive therapy, ${ }^{11}$ these efforts have failed to decrease overall TB disease burden in miners. Traditional approaches of both 'passive' and 'active' case finding and treatment ${ }^{12}$ have had limited impact on their TB incidence or clinical outcomes. Legacies of apartheid, poor treatment of miners and inadequate communication of company policies have fostered a culture of fear and mistrust ${ }^{13}$ such that comprehensive health screening programs, especially when mandatory, could be construed as employer-driven efforts to cull the workforce or improve company profits. ${ }^{14}$ Although the social implications of living 
with TB (e.g., fear, shame, stigma) are well described, ${ }^{15-17}$ the lived experiences of miners, including their barriers to and preferences for care, have not been studied.

The interplay of historical context with persistent disease burden urgently calls for innovative, interdisciplinary approaches to healthcare delivery in mining communities. The complexity of the problem necessitates clarifying the social, economic, and political influences that can strengthen healthcare delivery strategies in specific contexts. Therefore, we conducted qualitative research among miners/ex-miners, their families, healthcare providers, and local policymakers/managers in South Africa to identify the unique social and behavioral health determinants for successful TB care delivery and treatment.

\section{Study Population, Setting and Methods}

We conducted an applied ethnography ${ }^{18}$ of TB care delivery in the South African mining sector. Key stakeholders were miners/ex-miners, their family and community members, healthcare providers, and local policymakers and managers. Miners/ex-miners were South African or nationals of labor-sending countries currently or previously employed by one or more mine companies in South Africa. Family/community members included spouses and children of miners and their neighbors living in South Africa. Healthcare providers encompassed doctors, nurses, community health workers from the public health sector, and home-based care organizations. Healthcare policymakers/managers were from mining companies, district or provincial health departments, or nongovernmental organizations involved in the health of miners. 
We trained six field researchers in ethnographic methods of conducting formal and informal interviews, field notes, participant observation, and data analysis with thematic analysis and grounded theory. ${ }^{19-23}$ We collected data from West Rand District in Gauteng Province, and O. R. Tambo and Chris Hani Districts in Eastern Cape Province. These locations were suggested by health officials from the South African Medical Bureau of Occupational Diseases and University of the Witwatersrand for existing interest and efforts to integrate occupational health and compensation services for miners/ex-miners.

\section{Recruitment}

We used both snowball and convenience sampling. Recognizing the value of peer-to-peer trust among marginalized populations, we relied on key informants' personal and professional contacts to recruit in communities. Our access to current miners was limited; thus, we focused on recruiting ex- miners. Verbal informed consent was obtained after sharing information sheets and discussion with participants to ensure individual understanding and acceptability.

\section{Participant Observation and Interviews}

We observed ex-miners, their families and neighbors engaging in their usual activities in their homes and communities. We spent time in government offices and clinical facilities, making note of patient flow, clinical encounters, and health department operations. We collected observational data in multiple settings to support the validation of content.

We developed a topic guide for interviews and focus groups that we pilot tested with community members in South Africa, and iteratively modified (Table 1). Working in pairs balanced for 
Table 1. Standard in-depth interview and focus group discussion questions by participant group.

\begin{tabular}{|c|c|}
\hline Participants & Interview questions* \\
\hline $\begin{array}{l}31 \text { Miners/ex- } \\
\text { miners }\end{array}$ & $\begin{array}{l}\text { How and why did you start working in the mines? } \\
\text { What was it like being recruited to work in the mines? } \\
\text { What types of information were you give about safety concerns and the work you } \\
\text { would be doing in the mines? } \\
\text { Can you tell me what you know about tuberculosis? Where did you get this } \\
\text { information? } \\
\text { Before you became a miner, did anyone ever talk to you about the risk of getting } \\
\text { tuberculosis from working in a mine? Who was that? What did they tell you? } \\
\text { Can you describe your or others' experiences with the mining company clinic? When } \\
\text { do you go there? For what types of problems? How are you treated? } \\
\text { Who are the most important people in your daily life? } \\
\text { Tell me how you would you describe a typical visit to the health center. } \\
\text { What are the most important ways to talk about health with you and your friends? }\end{array}$ \\
\hline $\begin{array}{l}13 \text { Family and } \\
\text { community } \\
\text { members }\end{array}$ & $\begin{array}{l}\text { Tell me about yourself and your family. } \\
\text { Describe a typical day for you. } \\
\text { What happens if someone gets sick? } \\
\text { Can you tell me what you know about tuberculosis? Where did you get this } \\
\text { information? } \\
\text { Where does someone go if they are ill? Who are the people you would ask if you had } \\
\text { a health question? } \\
\text { How do you feel about the services that are offered in your community? } \\
\text { In general, what words would you use to describe your health? How might you }\end{array}$ \\
\hline
\end{tabular}




\begin{tabular}{|c|c|}
\hline & describe the health of your friends and relatives? \\
\hline $\begin{array}{l}14 \text { Clinicians/ } \\
\text { healthcare } \\
\text { workers }\end{array}$ & $\begin{array}{l}\text { Describe a typical day at the clinic. Who do you see? How do you help them? } \\
\text { What do you do if a miner is diagnosed with tuberculosis? } \\
\text { If a miner visits the clinic and complains of respiratory problems or coughing, what } \\
\text { do you do? } \\
\text { What do you think are the main reasons that a miner might not complete his TB } \\
\text { therapy? } \\
\text { Tell me what your thoughts and feelings are related to getting health care }\end{array}$ \\
\hline $\begin{array}{l}47 \text { Healthcare } \\
\text { policymakers and } \\
\text { managers }\end{array}$ & $\begin{array}{l}\text { What is the relationship between working in the mines and tuberculosis? } \\
\text { What responsibilities do the mining companies have if an employee is diagnosed } \\
\text { with TB? } \\
\text { In your opinion, what are the biggest barriers to implementing more widespread TB } \\
\text { testing? } \\
\text { If a miner has TB, where are they diagnosed and treated? How do you feel about the } \\
\text { services that are offered? } \\
\text { What do you think are the best ways for miners and their families to receive health } \\
\text { information about TB? }\end{array}$ \\
\hline
\end{tabular}

*We completed in-depth interviews with each of the 31 miners/ex-miners and 13 family/community members, and with 7 of the healthcare workers and 3 of the managers/policymakers. We also conducted 3 focus groups with healthcare workers and 2 with managers/policymakers, with 5-8 participants present at each. 
gender, ethnicity, and disciplinary background, we conducted focus groups and informal and formal interviews, audio-recording them when permitted. We also collected narratives through informal interviews with study participants. ${ }^{24}$

\section{Data Collection and Analysis}

Our research team daily reviewed research protocols and data collected for reliability. Members submitted daily and weekly summaries to aid recall of observed differences in experiences and to provide thick description for the subsequent analysis of context.

Multilingual team members translated interviews and focus group data collected in Tswana, Sesotho, Zulu, or Xhosa into English, and entered these into a database. Transcripts were qualitatively assessed using a grounded theory approach, as described in the literature. ${ }^{25,26} \mathrm{We}$

patterned our analysis on the procedures outlined by Corbin and Strauss. ${ }^{27}$ This approach is widely recognized as an effective methodology for analyzing large amounts of complex observational and interview data. ${ }^{23,25,28,29}$

The iterative analysis process involved three cyclical steps: 1) individual analysis; 2) small group discussion and thematic analysis; and 3) consensus through triangulation of small group analysis. First, field notes were individually summarized then grouped by emergent themes. In step 2, two groups of analysts determined the most salient themes by repeated review, selected narratives that best reflected those themes, and independently proposed a representative model. Finally, both groups came together to finalize findings. Disagreements were resolved through discussion and group consensus. 
The Institutional Review Boards of Dartmouth College, University of the Witwatersrand, Eastern Cape Province Health Department, and West Rand District Health Department approved the study.

\section{Results}

We completed 54 ethnographic interviews and 5 focus groups with 30 miners/ex-miners, 13 family/community members, 14 healthcare providers, and 47 policymakers/managers (Table 1). Participant demographics and interview specifics are described in Table 2. We labeled the strongest TB-associated theme that emerged as the "masking of TB." This "masking" combines widespread lack of knowledge about TB, the stigma and fear that result in part from lack of knowledge, and the structural and symbolic violence that occur when TB is hidden from public consciousness.

\section{Widespread Lack of Knowledge about TB}

Miners/ex-miners and their family/community members knew little about TB clinical features, how it is spread, or how it is treated. Many miners/ex-miners believe that TB is caused by dust underground or from the large mounds of mining waste near the mine surface. Such misunderstanding contributed to the unintentional spread of disease to co-workers and family members. It may also have led to risks of re-infection, which miners described as how TB can "retake" them or is "recycled" in their bodies. 
Table 2. Demographics of participants interviewed and interview specifics.

\begin{tabular}{|c|c|c|c|c|c|}
\hline Participants & Number & $\begin{array}{l}\text { Age } \\
\text { Range } \\
\text { (years) }\end{array}$ & Current profession & $\begin{array}{l}\text { Location of } \\
\text { interview }\end{array}$ & $\begin{array}{l}\text { Type of } \\
\text { interaction }\end{array}$ \\
\hline $\begin{array}{l}\text { Miners / ex- } \\
\text { miners }\end{array}$ & 30 & $28-66$ & $\begin{array}{l}\text { Underground miner; } \\
\text { unemployed, informal } \\
\text { work, contract work, part- } \\
\text { time work }\end{array}$ & $\begin{array}{l}\text { Home, public park, } \\
\text { clinics, One-Stop } \\
\text { Clinics }\end{array}$ & $\begin{array}{l}\text { Informal } \\
\text { interview, } \\
\text { Interviews and } \\
\text { focus group }\end{array}$ \\
\hline $\begin{array}{l}\text { Family and } \\
\text { community } \\
\text { members }\end{array}$ & 13 & $23-57$ & $\begin{array}{l}\text { Unemployed, professor, } \\
\text { informal work, student, } \\
\text { homemaker, service } \\
\text { industry }\end{array}$ & $\begin{array}{l}\text { Homes, clinics, } \\
\text { community public } \\
\text { spaces }\end{array}$ & $\begin{array}{l}\text { Interviews and } \\
\text { focus groups }\end{array}$ \\
\hline $\begin{array}{l}\text { Clinicians/he } \\
\text { althcare } \\
\text { workers }\end{array}$ & 14 & $33-56$ & $\begin{array}{l}\text { Physicians, nurses, home- } \\
\text { based care, community } \\
\text { health worker }\end{array}$ & $\begin{array}{l}\text { Clinics, hospitals, } \\
\text { One-Stop Clinics }\end{array}$ & $\begin{array}{l}\text { Formal and } \\
\text { informal } \\
\text { interviews }\end{array}$ \\
\hline $\begin{array}{l}\text { Healthcare } \\
\text { policymakers } \\
\text { and managers }\end{array}$ & 47 & N/A & $\begin{array}{l}\text { District officials, province } \\
\text { officials, MBOD, NGO } \\
\text { managers, mining house } \\
\text { health managers, Chamber } \\
\text { of Mines }\end{array}$ & $\begin{array}{l}\text { Clinics, hospitals, } \\
\text { district health } \\
\text { offices, } \\
\text { organization offices }\end{array}$ & $\begin{array}{l}\text { Formal and } \\
\text { informal } \\
\text { interviews }\end{array}$ \\
\hline
\end{tabular}


Miners/ex-miners were confused about the employment consequences once diagnosed with TB. While policy dictates that miners are not fired because of TB, several ex-miners told us about being "asked to leave" their job as a result of their TB. Miners diagnosed with TB reported being told there were no other opportunities for them in "friendlier or safer locations". Similarly, family members had limited knowledge about TB. One miner's son described his experience, saying, "I don't know how I got the TB or what kind of TB it is" and another who was convinced, “...it's a disease where you are going to die... that's why I didn't want to hear someone saying 'you've got that TB...It's a death sentence."

Many miners/ex-miners told us that their company did not provide appropriate TB education during their employment; any TB education occurred only during induction trainings, without opportunities for clarification. One miner said the problem with TB education campaigns in the mines is that, "Those posters of TB, they just put it on the wall, they don't explain it to a person." During a mine visit, our team observed dozens of unclear or complicated health posters and TV screens that repeated the same safety video every 10 minutes. Miner education also did not appear to address how health is tied to job security, educational opportunities, or prevailing negative attitudes towards or experiences with existing healthcare systems.

Once diagnosed and on treatment, miners felt they rarely received accurate, relevant information about their illness at the mine clinics. A man whose father died from TB while working in a mine reported that when his father "fell ill again and consulted a doctor in the mine hospital, they only told him that he had 'chest problems' and not necessarily that he had TB". A lack of information 
about how successful TB treatment can be led miners to believe "TB is incurable even when you take your treatment, we know that; because this thing is in your lungs and lungs are life".

We learned how limited health education was for families. Although wives often served as caregivers, many reported that neither the mining companies nor local health facilities provided them with TB information. As a miner's widow said, "the nurses and doctors would never explain anything to us, we would be excluded from the consultation".

\section{TB Stigma, Fear and Distrust of the Healthcare System}

Miners often denied having symptoms to their families given the shame associated with TB, and its association with HIV. One miner explained how illness-related discrimination in families reflects misperceptions that weight loss, weakness, and coughing up blood are contagious and lead to death. As families noted, miners/ex-miners with these symptoms have died with a diagnosis of HIV and TB. While families have ample direct experience that miners/ex-miners bring sickness and death from the mines, this sometimes led to assumptions and accusations rather than support. In one instance, a miner recalled being reproached that he "coughs too much" and that he "must still have TB." Indicative of many miners/ex-miners' experiences, these micro-aggressions produced a feeling of severe isolation when ill. Consequently, many miners/ex-miners reported rarely sharing their experiences of living with, or surviving, TB with their families.

Miners/ex-miners felt negatively about their interactions with the healthcare system and clinicians. Several reported experiences that left them doubtful that hospitals are places for 
healing. One ex-miner stated: “The hospital is a storeroom where you go to die." Many of the men we spoke with would delay visiting a doctor out of fear and potentially a lack of perceived social and instrumental support. Some reported self-delaying access to TB care; others were eventually dragged to a clinic by their wives or transported by ambulance because their illnesses had progressed so far that they collapsed.

When we asked miners/ex-miners who they trusted, they described the strong bonds they formed with their co-workers, and how, because of the dangerous working conditions, they literally placed their lives in their co-workers' hands. One ex-miner relayed "Anyone that I was working with, I took him as my friend because I was working along him... you know in the mines, if you don't cooperate with the people that you are working with, you can easily be trapped." This cooperation also led to shared experiences and friendships that provided support during difficult times including illness. However, given the shared lack of knowledge about its cause and how to protect themselves from TB, often all miners could do was bear witness to others' suffering. As one ex-miner expressed, "I was working with another guy, he was a miner. He was afraid to go to the hospital...He died underground, that one I can witness it, he died underground". Seeing friends die from TB perpetuated miners/ex-miners' fear and sense of powerlessness.

\section{The clinician's perspective: whose responsibility?}

Most healthcare workers interviewed were unable to acknowledge the socioeconomic and cultural determinants affecting their patients' understanding or perception of illness. Clinicians appeared to blame patients for poor treatment adherence. One nurse became very upset talking about her patients who interrupt their TB treatment, saying, "it's on your behavior" because the 
mine is "putting a lot of energy in you" with health education campaigns and free medication. She said she felt like asking those who discontinued treatment "Why are you killing yourself?" We heard many clinicians shift the responsibility for managing TB from the clinician or system to the patient. One clinician in a district meeting said "clients don't understand that they need to do their part for us to do our part." Healthcare workers rarely recognized the challenges their patients face in accessing or adhering to treatment - challenges that include the social and medical dislocations of migration, stigma and mistrust, and economic hardship. Healthcare workers routinely blamed the habits of individual patients for the high rates of TB without attributing any contribution from inadequate counsel or clinician behavior. This was most evident in discussions with stakeholders at the managerial level who spoke about difficult, uneducated, or noncompliant patients.

\section{Policymakers/managers: issues too difficult to face}

Policymakers/managers were generally interested in our research and admitted they had not previously collected such data. During a group interview, a policymaker stated that it's much easier to avoid seeing and hearing stories from the field because it affects her work. We were told, "this is why your work is so important, because you connect us to what's actually happening on the ground, when those stories are just too hard to hear." Such attitudes among these stakeholders contribute directly to the "masking" of TB.

Policymakers/managers told us that stakeholders talk about the TB epidemic among miners and discuss possible solutions; however, accountability is diffuse and implementation challenges remain unsolved. Conversations with policymakers/managers revealed a general resignation due 
to the broad social factors (e.g., fear, stigma, apartheid legacy) that further complicate the problem. One interviewee described it as a collective malaise in addressing the TB epidemic. Some suggested that an analysis of the failed systemic approaches to TB among miners might reveal the origins of the fear and misinformation that masked TB and contributed to their poor outcomes. One mining organization manager was hopeful that "You can have a system that's supportive enough to actually get people to come on treatment." Overall, administrators expressed motivation to address TB in miners but felt overwhelmed by the bureaucracy and their ability to effect change.

\section{Discussion}

Our novel qualitative findings are the first to examine social and behavioral determinants of TB and care delivery among miners/ex-minters, their families/communities, healthcare providers, and policymakers/managers in South Africa. Our structured observations reveal a widespread lack of knowledge and understanding that contribute to the "masking of TB" - despite health promotion activities in mines and clinics. The further exacerbation of stigma and fear associated with TB manifests in ex-miners as a denial of symptoms, delays in care-seeking, and a distrust of the healthcare system. Among families it appears as misinformation and incomplete understanding of TB risk, treatment, and prevention. Longstanding stigma and discrimination in the TB care pathway has been well documented. ${ }^{30-35}$

Stigma and the association of TB with HIV and what healthcare providers and policymakers labeled "negative behaviors" can decrease patients' willingness to be evaluated for TB and cause them to interrupt their treatment. ${ }^{30-35}$ However, this masking extends beyond knowledge gaps 
and stigma; it is an articulation of symbolic and structural violence. Masking TB brings new forms of risk and vulnerability, as well as the possibility for healthcare workers and policymakers to place the onus on patients and avoid dealing with entrenched health inequalities and the need for structural changes to current healthcare delivery systems. ${ }^{36,37}$ Our data also suggest that local experiences of living with and surviving TB are unknown to the clinicians, managers, and policymakers we interviewed. This limits public awareness and the potential for adapting healthcare services to the miners' context.

Interventions responsive to these findings would include shifting to community-based education to improve care-seeking behaviors among miners and to provide families/communities a chance to collectively respond to reduce stigma. More attention to lay health education and promotion among local support systems further benefit family and community caregiving. Studies in rural Ethiopia and Nicaragua have shown that interventions to improve knowledge and address stigma, such as the initiation of local TB support groups, can improve care-seeking behavior, clinic attendance, and treatment completion among TB patients. ${ }^{38-40}$ Furthermore, such patientbased groups can improve patients' understanding of TB - including initial reactions to diagnosis - and build better attitudes in the community regarding TB. ${ }^{38-40}$

Clinicians serving miners adhered to the prevailing biomedical model that holds TB patients responsible for contracting their disease and for treatment adherence. ${ }^{41}$ Still, many clinicians were eager for new approaches to better serve their patients. Under a co-designed delivery model, clinicians trained in shared-decision making and motivational interviewing would learn to address their patients' shame and guilt about having TB and engage them in their care and 
treatment. Blaming patients fails to recognize the interdependence of providers and patients, and to account for broader socio-ecological factors that influence people's health behaviors and preferences, and ability to get the necessary support to adhere to treatment. ${ }^{40}$

Among policymakers/managers, the masking of TB articulates, in part, as poor communication with patients, families, and clinicians, which has resulted in implementation challenges for TB management and treatment. Furthermore, the longstanding and socially complex nature of TB in the mining sector has caused policymakers/managers to feel overwhelmed, constraining them in effectively identifying problems and seeking and implementing solutions with others, including miners/ex-miners and their families/communities.

Several approaches to overcome this masking of TB can be derived from our findings. First, it is time to move beyond patient-centered care (which is often based on assumptions about patients' needs) to a patient co-designed model that will provide preference-sensitive care delivery.

Miners and their families clearly articulated their needs and preferences for how, from whom and where they would like to receive care. Furthermore, miners must receive health education and employment information regarding TB in ways that are accessible and meaningful to them, from people they know and trust. Our research suggests that current or former miners are an untapped resource and the ideal cohort to conduct health education and what the public health system calls 'case management' but what might be reframed by miners as 'patient support'. Despite their diverse backgrounds, ex-miners bring the shared culture of the mine to their interactions; this, in turn, fosters trust and credibility. Ex-miners should be recruited into existing community health worker programs in South Africa. A study in a rural district of KwaZulu-Natal showed that well- 
trained community care workers decreased stigma and discrimination and enhanced TB and HIV care, including improved case finding, TB contact tracing, and linkages to care. ${ }^{42}$ Despite the differences between a mining community and a rural village, the success of this program is promising for similar interventions among miners. This approach would also promote employment after mining and build stronger relationships between mining communities and the healthcare system.

At the health system level, the healthcare delivery redesign process should improve clinician and manager accountability and emphasize patient priorities and satisfaction. This could be done by collecting and disseminating patient-reported outcome data and allocating resources to interventions with the greatest success. Sharing TB case finding and treatment outcomes data among care teams may encourage competition towards improvement and support best practices. In addition, healthcare delivery should use measures and tools that empower clinicians to deliver, and patients to receive, care that is responsive to individual and population preferences. These measures and tools should be co-developed with miners to help clinicians and policymakers/managers better meet miners' needs.

Educational programs for healthcare workers may prove beneficial. A Cape Town study of a healthcare worker educational program found that poor patient-provider communication adversely affects patients' treatment adherence. ${ }^{43}$ The educational program encouraged healthcare providers to consider what patients wanted to know about $\mathrm{TB}$, and the problems and difficulties of TB treatment from patient perspectives. Overall, healthcare providers found the 
intervention useful and thought it helped them work better as a team and with their patients, although there were many structural barriers to long-term change. ${ }^{43}$

A limitation of our study was that we had minimal access to current miners due to mining company restrictions; we only interviewed one employed miner and 29 former miners. It is possible that the experiences of ex-miners might differ from those presently mining. However, since the range of time since mine employment was 5-10 years and the data supporting the dominant theme were consistent and reinforced by triangulation, it seems unlikely that circumstances were significantly different. Another limitation is that most of our interviewees were South African. Our findings may not be generalizable to the miners and/or families of labor-sending countries. While it is unlikely that the concerns identified by our interviewees are South African-specific, a broader study that includes participants from the labor-sending communities would clarify regional differences.

\section{Conclusion}

These findings contribute new understanding of the long-term effects that the masking of TB in Southern Africa has on perpetuating disempowerment, stigma, and inadequate care among miners/ex-miners and their families/communities. Healthcare workers' and managers' efforts to address TB among miners are constrained by limitations of the current care system. New approaches are urgently needed. Engaging miners in redesigning care delivery could be a gamechanger to address the unacceptable TB burden in this population. 
Acknowledgements: The authors acknowledge the participants in this study who shared their stories and lives with us. We also acknowledge critical support from Mr. Vama Jele of the Swaziland Migrant Mineworkers Association, Professor Thea de Wet of the University of Johannesburg, South Africa, Dr. T.E. Selebano of the Gauteng Department of Health, South Africa, colleagues at the South African Ministry of Health, and our many South African community partners. Lastly, we thank Elizabeth A. Talbot, MD of Dartmouth-Hitchcock Medical Center for her careful technical review of the manuscript.

Funding: This research was supported by funding from the World Bank.

Conflicts of interest: None

Author contributions: LVA, SG, SC, AGM, MP, and PO conceived of and designed the study; DB, SG, MP, AS, KN, NP, VTR collected the data with supervision from DB and SG; all authors contributed to data analysis; MP, SG, LVA and AGM led the write up of findings with input from all authors.

\section{References}

1. Tuberculosis Strategic Plan for South Africa, 2007-2011. Pretoria, South Africa: Ministry of Health; 2007.

2. Targeted tuberculin testing and treatment of latent tuberculosis infection. American Thoracic Society. MMWR Recomm Rep. 2000 Jun 9;49(RR-6):1-51.

3. Churchyard GJ1, Kleinschmidt I, Corbett EL, Murray J, Smit J, De Cock KM. Factors associated with an increased case-fatality rate in HIV-infected and non-infected South 
African gold miners with pulmonary tuberculosis. Int J Tuberc Lung Dis. 2000 Aug;4(8):705-12.

4. Corbett EL, Churchyard GJ, Clayton T, Herselman P, Williams B, Hayes R, Mulder D, De Cock KM. Risk factors for pulmonary mycobacterial disease in South African gold miners. A case-control study. Am J Respir Crit Care Med. 1999 Jan;159(1):94-9.

5. Corbett EL, Churchyard GJ, Clayton TC, Williams BG, Mulder D, Hayes RJ, De Cock KM. HIV infection and silicosis: the impact of two potent risk factors on the incidence of mycobacterial disease in South African miners. AIDS. 2000 Dec 1;14(17):2759-68.

6. Rees D, Murray J. Silica, silicosis and tuberculosis. Int J Tuberc Lung Dis. 2007 May;11(5):474-84.

7. Olivier, M. Regional Overview of Social Protection for Non-Citizens in the Southern African Development Community (SADC). Social Protection Discussion Paper Series No. 0908, The World Bank-Social Protection Advisory Service, Washington, D. C. , 2009.

8. Hermans SM, Grant AD, Chihota V, Lewis JJ, Vynnycky E, Churchyard GJ, Fielding KL. The timing of tuberculosis after isoniazid preventive therapy among gold miners in South Africa: a prospective cohort study. BMC Med. 2016 Mar 23;14:45.

9. Lim MS, Dowdeswell RJ, Murray J, Field N, Glynn JR, Sonnenberg P. The impact of HIV, an antiretroviral programme and tuberculosis on mortality in South African platinum miners, 1992-2010. PLoS One. 2012;7(6):e38598.

10. Charalambous S, Grant AD, Moloi V, Warren R, Day JH, van Helden P, Hayes RJ, Fielding KL, De Cock KM, Chaisson RE, Churchyard GJ. Contribution of reinfection to recurrent tuberculosis in South African gold miners. Int J Tuberc Lung Dis. 2008 Aug;12(8):942-8. 
11. Churchyard GJ, Fielding KL, Lewis JJ, Coetzee L, Corbett EL, Godfrey-Faussett P, Hayes RJ, Chaisson RE, Grant AD; Thibela TB Study Team. A trial of mass isoniazid preventive therapy for tuberculosis control. N Engl J Med. 2014 Jan 23;370(4):301-10.

12. World Health Organization. Systematic screening for active tuberculosis: principles and recommendations. WHO/HTM/TB/2013.04. Geneva, Switzerland: WHO, 2013. http://www.who.int/iris/bitstream/10665/84971/1/9789241548601_eng.pdf?ua=1. Accessed December 2016.

13. Packard RM. White plague, black labor: tuberculosis and the political economy of health and disease in South Africa. ${ }^{\text {st }}$ ed. Berkeley, USA: University of California Press, 1989, pp $1-378$.

14. Basu S, Stuckler D, Gonsalves G, Lurie M. The production of consumption: addressing the impact of mineral mining on tuberculosis in southern Africa. Global Health. 2009 Sep 29;5:11. doi: 10.1186/1744-8603-5-11.

15. Cramm JM, Finkenflügel HJ, Møller V, Nieboer AP. TB treatment initiation and adherence in a South African community influenced more by perceptions than by knowledge of tuberculosis. BMC Public Health. 2010 Feb 17;10:72. doi: 10. 1186/1471-2458-10-72.

16. Edginton ME, Sekatane CS, Goldstein SJ. Patients' beliefs: do they affect tuberculosis control? A study in a rural district of South Africa. Int J Tuberc Lung Dis. 2002 Dec;6(12):1075-82.

17. Munro SA, Lewin SA, Smith HJ, Engel ME, Fretheim A, Volmink J. Patient adherence to tuberculosis treatment: a systematic review of qualitative research. PLoS Med. 2007 Jul 24;4(7):e238. 
18. Lambert H, McKevitt C. Anthropology in health research: from qualitative methods to multidisciplinarity. BMJ. 2002 Jul 27;325(7357):210-3.

19. Briggs CL. Learning how to ask: A sociolinguistic appraisal of the role of the interview in social science research. Cambridge: Cambridge University Press; 1986. 155 p.

20. Atkinson P, Hammersley M. Ethnography and participant observation. In: Denzin NK, Lincoln YS, editors. Handbook of Qualitative Research. Thousand Oaks: Sage Publications; 1994. p. 248-61.

21. Savage J. Participative observation: standing in the shoes of others? Qual Health Res. 2000 May;10(3):324-39.

22. Becker HS, Geer B. Field methods and techniques participant observation and interviewing : A comparison. Hum Organ. 1957;16(3):28-32.

23. Emerson RM, Fretz RI, Shaw LL. Writing Ethnographic Fieldnotes. $2^{\text {nd }}$ ed. Chicago, USA: University of Chicago Press, 2011: pp 1-320.

24. Witzel A. The problem-centered interview. Forum Qualitative Sozialforschung / Forum: Qualitative Social Research, 1(1), Art. 22, http://nbn-resolving. de/urn:nbn:de:0114fqs0001228.

25. Charmaz K. 2006 Constructing Grounded Theory: A Practical Guide Through Qualitative Analysis. London; Thousand Oaks California: Sage Publications; 2006.

26. Braun V, Clarke V. Using thematic analysis in psychology. Qual Res Psychol. 2006 Jan;3(2):77-101.

27. Corbin JM, Strauss A. Grounded theory research: Procedures, canons, and evaluative criteria. Qual Sociol. 1990 13(1):3-21. doi:10.1007/BF00988593. 
28. Patton M. Enhancing the quality and credibility of qualitative analysis. Health Serv Res. 1999 Dec;34(5 Pt 2):1189-208.

29. Patton M. Qualitative evaluation and research methods. $3^{\text {rd }}$ ed. Thousand Oaks, USA: Sage Publications, Inc., 2002: pp 1-589.

30. Murray EJ, Bond VA, Marais BJ, Godfrey-Faussett P, Ayles HM, Beyers N. High levels of vulnerability and anticipated stigma reduce the impetus for tuberculosis diagnosis in Cape Town, South Africa. Health Policy Plan. 2013 Jul;28(4):410-8.

31. Rowe KA, Makhubele B, Hargreaves JR, Porter JD, Hausler HP, Pronyk PM. Adherence to TB preventive therapy for HIV-positive patients in rural South Africa: implications for antiretroviral delivery in resource-poor settings. Int J Tuberc Lung Dis 2005 9(3):263-9.

32. Bond V, Nyblade L. The importance of addressing the unfolding TB-HIV stigma in high HIV prevalence settings. J Community Appl Soc Psychol 2006 16:452-461.

33. Szakacs TA, Wilson D, Cameron DW, Clark M, Kocheleff P, Muller FJ, McCarthy AE. Adherence with isoniazid for prevention of tuberculosis among HIV-infected adults in South Africa. BMC Infect Dis 2006 6(97):1.

34. Daftary A. HIV and tuberculosis: the construction and management of double stigma. Soc Sci Med. 201274 (10):1512-9.

35. Getahun H, Maher D. Contribution of 'TB clubs' to tuberculosis control in a rural district in Ethiopia. Int J Tuberc Lung Dis 2000; 4: 174-178.

36. Farmer P, Nizeye B, Stulac S, Keshavjee S. Structural violence and clinical medicine. PLOS Med. 2006 Oct;3(10):e449.

37. Farmer P. Pathologies of power: health, human rights, and the new war on the poor. $1^{\text {st }}$ ed. Berkeley, USA: University of California Press, 2003: pp 1-378. 
38. Demissie M, Getahun H, Lindtjorn B. Community tuberculosis care through 'TB clubs' in rural North Ethiopia. Soc Sci Med 2003; 56: 2009-2018.

39. Macq J, Solis A, Martinez G, Martiny P. Tackling tuberculosis patients' internalized social stigma through patient centred care: an intervention study in rural Nicaragua. BMC Public Health 2008; 8:154.

40. Dolezal L. The phenomenology of shame in the clinical encounter. Med Health Care Philos. 2015 18(4):567-76.

41. Ortblad KF, Salomon JA, Bärnighausen T, Atun R. Stopping tuberculosis: a biosocial model for sustainable development. Lancet. 2015;386(10010):2354-62.

42. Uwimana J, Zarowsky C, Hausler H, Jackson D. Training community care workers to provide comprehensive TB/HIV/PMTCT integrated care in KwaZulu-Natal: lessons learnt. Trop Med Int Health. 2012 Apr;17(4):488-96.

43. Dick J, Lewin S, Rose E, Zwarenstein M, Walt H. Changing professional practice in tuberculosis care: an educational intervention. J Adv Nurs. 2004 Dec;48(5):434-42. 